\title{
Maternal Perception on Obesity; Its Complications and Gestational Weight Gain in Pregnant Mothers Presenting to Antenatal Clinics in a South Asian Teaching Hospital (De Soyza Hospital for Women Colombo-DSHW)
}

\author{
Wijemunige Chamara Charith Gunathilaka1, Surangi Nilanka Jayakody², \\ Senani Hemantha Dodampahala ${ }^{3 *}$, Thavendra Kumaran ${ }^{4}$ \\ ${ }^{1}$ Senior House Officer, De Soyza Hospital for Women, Colombo, Sri Lanka \\ ${ }^{2}$ Lecturers in Community Medicine, Faculty of Medical Sciences, University of Sri Jayewardenepura, Colombo, Sri Lanka \\ ${ }^{3}$ Obstetrics and Gynecology, Professorial Unit, De Soyza Hospital for Women, Colombo, Sri Lanka \\ ${ }^{4}$ Faculty of Medicine, University of Colombo, Colombo, Sri Lanka \\ Email: `hdodampahala@obg.cmb.ac.lk, „hemdodam@gmail.com, tkumaran26@gmail.com
}

How to cite this paper: Gunathilaka, W.C.C., Jayakody, S.N., Dodampahala, S.H. and Kumaran, T. (2019) Maternal Perception on Obesity; Its Complications and Gestational Weight Gain in Pregnant Mothers Presenting to Antenatal Clinics in a South Asian Teaching Hospital (De Soyza Hospital for Women Colombo-DSHW). Advances in Reproductive Sciences, 7, 21-30. https://doi.org/10.4236/arsci.2019.72004

Received: February 2, 2019

Accepted: March 9, 2019

Published: March 12, 2019

Copyright $\odot 2019$ by author(s) and Scientific Research Publishing Inc. This work is licensed under the Creative Commons Attribution International License (CC BY 4.0).

http://creativecommons.org/licenses/by/4.0/ (c) (i) Open Access

\begin{abstract}
The rates of overweight and obesity are rising to epidemic proportions globally, especially among women. Obesity is increasingly common in the obstetric population as well. Sri Lanka is not an exception to this regard. There is limited published data on maternal perceptions on obesity in pregnancy, gestational weight gain and its complications. The current study aimed to describe the maternal perception on obesity, their knowledge on complications of obesity in pregnancy and gestational weight gain in pregnant mothers. Hospital based descriptive cross sectional study was conducted among a systematic sample of 416 pregnant women registered for antenatal clinic care at De Soyza Maternity Hospital. Pre-tested interviewer administered questionnaire was used for data collection. Maternal BMI at booking visit was taken from the pregnancy record to assess the overweight/obesity prevalence among the study population. Nearly one third (32.2\%) of the study population were overweight and $11.8 \%$ were obese. Fifty three percent $(53 \%)$ of overweight women identified themselves as such, but $45 \%$ of them considered themselves to be normal weight. Most of the pregnant women in the study sample $(59.6 \%)$ were unable to estimate the recommended weight gain in pregnancy. Women's knowledge on the specific risks associated with maternal obesity was poor. Pregnant mother's knowledge on obesity, gestational weight gain and its consequences were unsatisfactory. Bridging this knowledge gap is an important step towards improving perinatal outcomes for all pregnant mothers in the current obesity epidemic.
\end{abstract}




\section{Keywords}

Overweight, Obesity, Gestational Weight Gain, Maternal Complications, Medical Nutrition Therapy, South Asia

\section{Introduction}

World Health Organization (WHO) has recognized obesity as one of the most important public health problems facing the world today. The rates of overweight and obesity are rising to epidemic proportions, especially among women [1]. Overweight and Obesity are defined as a body mass index (BMI) of equal to or greater than $25 \mathrm{~kg} / \mathrm{m}^{2}$ and $30 \mathrm{~kg} / \mathrm{m}^{2}$ respectively. Sri Lanka is not an exception regarding overweight and obesity. A national survey conducted in 2012 found that $28.7 \%$ and $15.2 \%$ of women were overweight and obese respectively [2]. Obesity is increasingly common in the obstetric population as well. Global figures suggest there are more than 100 million obese women of child bearing age, with further 250 million who are overweight [1]. There is no specific data on obesity prevalence among Sri Lankan pregnant women.

There is a direct relationship between maternal overweight and increased risk of pregnancy complications [3]. Obese women are 3 times more likely to present with infertility compared with women of normal BMI, with the infertility rate increasing by $4 \%$ per BMI unit in obese women [1]. When they do conceive either naturally or through assisted techniques, there is an increased risk of miscarriage [3]. Ideally, BMI should be optimized preconception through diet and lifestyle counseling and specialized weight-reduction programmes. Obese mothers are at increased risk of getting fetal anomalies. Ultrasound examination is also difficult and less accurate due to poor visualization in obese mothers [3]. Maternal obesity and excessive gestational weight gain have well recognized associations with pre-eclampsia, gestational diabetes mellitus (GDM), instrumental or operative delivery, failed induction, prolonged labor, caesarian section, post partum hemorrhage, infections anesthetic complications and venous thromboembolism [3]. Maternal obesity is also associated with fetal macrosomia, increased perinatal morbidity and mortality, childhood obesity and diabetes [4].

The effect of maternal and social factors on gestational weight gain had also been studied. According to a cohort study done in Sri Lanka, being overweight, presence of maternal complications, passive smoking, low educational level and high income were the determinants of excessive weight gain during pregnancy [5].

Although the obesity, its complications and associated factors are well researched worldwide, there are limited published data on maternal perceptions on BMI in pregnancy, and the effect of this has on gestational weight gain and its complications. It has been demonstrated that overweight and obese pregnant women are less likely than women of normal weight to correctly assess their own BMI [6]. According to a study done in Australia, $47.8 \%$ of the study population was overweight or obese. Seventy four percent $(74 \%)$ of obese women underes- 
timates their BMI category. Sixty four percent (64\%) of obese women and $40 \%$ of overweight women overestimated their recommended gestational weight gain. Women's knowledge on the complications of excess gestational weight gain and maternal obesity was also poor [7].

\subsection{Justification}

Sri Lanka has well developed and comprehensive antenatal and post natal care services; almost $100 \%$ pregnant mothers were registered for antenatal care [8]. Women received antenatal care from several places from filed clinic to specialized clinic to private sector. The average number of antenatal clinic visits varies from 15 to 22 visits [9]. Other than the clinic care, pregnant women received domiciliary care from the public health midwives at their door step. In addition to antenatal services government of Sri Lanka provide pre-conception care services at fieldevel, where they assess the BMI of women and do necessary interventions. But women are less aware of these services and the coverage is also very low compared to antenatal care.

Weight gain in pregnancy remains a matter of great concern for women and health care provider. However, their concern on obesity and related issues are relatively low. Most Sri Lankan studies focus on inadequate maternal weight gain and its complications [10]. The information related to maternal perception on obesity is even scarce, though it is essential in terms of proper management of the current obesity epidemic. Bridging this knowledge gap will be an important step towards improving perinatal outcomes for all pregnant women, especially those who are overweight or obese at booking visit.

Therefore this study is aimed to describe maternal perception on obesity, its complications and gestational weight gain.

\subsection{General Objective}

To describe the maternal perception on obesity, their knowledge on complications of obesity in pregnancy and gestational weight gain in pregnant mothers attending antenatal clinics in the De Soyza Maternity Hospital-Colombo (DSHW).

\subsection{Specific Objectives}

1) To describe the maternal perception on obesity in pregnant mothers attending antenatal clinics in the De Soyza Maternity Hospital-Colombo (DSHW).

2) To describe the socio-demographic characteristics of the study sample.

3) To assess their knowledge on complications of obesity and gestational weight gain.

\section{Methods}

\subsection{Study Design}

Hospital based descriptive cross sectional study. 


\subsection{Study Population}

All pregnant women registered for antenatal clinic care at De Soyza Maternity Hospital at the time of the study

Study period: $1^{\text {st }}$ June 2017 to $31^{\text {st }}$ August 2017.

\subsection{Study Unit: Pregnant Women}

Exclusion criteria: Pregnant women who are mentally retarded or physically handicapped were excluded from the study. Pregnant women with diabetes mellitus prior to pregnancy were also excluded.

\subsection{Sample Size Calculation}

The following formula is used to calculate sample size [11];

$$
N=\frac{Z^{2} P(1-P)}{d^{2}}
$$

where,

$N$-Total sample size

$Z$-value corresponding to confidence limits

$d$-margin of error (Total width of confidence interval)

$P$-Expected population proportion

$P=43.9 \%$ (prevalence of overweight and obesity among Sri Lankan women, [12])

$Z=1.96$ (Critical value for 95\% confidence interval)

$d=0.05$ (Accepted amount of absolute error is considered as 5\%)

$$
\begin{gathered}
N=\frac{1.962 \times 0.439(1-0.439)}{(0.05)^{2}} \\
N=\frac{3.8416 \times 0.2462}{0.0025}
\end{gathered}
$$

$N=378$ to compensate for non respondents, $10 \%$ of the calculated sample size is added making total sample size as 416 .

\subsection{Sampling Technique}

De Soyza Maternity Hospital is a tertiary care hospital for women in Sri Lanka. The hospital has approximately 5000 deliveries per year with a wide mix of ethnicities represented. Required number of pregnant women was recruited using a systematic sampling method. Every third mother registered for the antenatal clinic care in a particular clinic day was recruited for the study until the final sample size was achieved.

\subsection{Study Instruments}

The data was collected using pre tested interviewer administered questionnaire which contained the following sections: 
- Socio-demographic information.

- Past and present obstetric history.

- Questions to assess maternal perception on obesity.

- Questions to assess their knowledge on complications of obesity and gestational weight gain.

Maternal BMI at booking visit was taken from the pregnancy record to assess the overweight/obesity prevalence among the study population.

\subsection{Data Collection}

Data was collected by pre-intern medical officers. The purpose of the study was explained to the pregnant women and informed written consent was taken.

\subsection{Data Analysis}

Data entry and analysis was done by using the Statistical Package for Social Sciences (SPSS) version 21.0. Quantitative data were described using frequency distribution and mean values.

Qualitative data were presented using percentages.

\subsection{Ethical Considerations}

Ethical clearance was obtained from the Ethics Review Committee of the National Hospital of Sri Lanka. Information sheet containing a comprehensive description about the purpose of the study, its importance and benefits was given to each participant and they were given adequate time to read it and clarify any doubts regarding the study. If the participant agreed to answer the questions, informed written consent was taken prior to the interview.

\section{Results}

\section{Description of the study sample}

Age of the antenatal women in the study sample ranged from 19 to 43 years, with a mean age of 27 years $(S D=5.146)$ and most women $(58 \%)$ were aged between 25 to 34 years. Of the 416 participants 366 (88\%) were Sinhalese, 19 (4.6\%) were Tamils and 31 (7.5\%) were Muslims.

All the antenatal mothers in the study population had gone to school. Among all 195 (47\%) had studied up to G.C.E Ordinary level. Higher educational attainments such as a diploma, a degree or above had been achieved by $12 \%$. But $291(70 \%)$ were house wives. Out of the $30 \%$ who were employed, most (18\%) were in clerical and related jobs.

According to the total family income as reported by the mothers, 312 (75\%) were getting more than Rs. 10,000. But there were 75 (18\%) with no permanent income.

\section{Reproductive Health Characteristics of the study sample}

Most of the antenatal women (58\%) were in their first pregnancy. 56\% have planned their pregnancy. When categorized the sample according to POA, 182 
(43.8\%) were in $3 \mathrm{rd}, 139(33.4 \%)$ were in $2^{\text {nd }}$ and $95(22.8 \%)$ were in $1^{\text {st }}$ trimester. Most of them (59\%) had registered for antenatal care before 8 weeks of POA.

Body Mass Index of the study sample

When women were classified according to BMI, 193 (46.4\%) were normal weight (BMI $\left.18-24.9 \mathrm{~kg} / \mathrm{m}^{2}\right), 40(9.6 \%)$ were classified as underweight (BMI < $\left.18 \mathrm{~kg} / \mathrm{m}^{2}\right), 134(32.2 \%)$ were overweight (BMI $\left.25-29.9 \mathrm{~kg} / \mathrm{m}^{2}\right)$ and $49(11.8 \%)$ were obese $\left(\mathrm{BMI}>30 \mathrm{~kg} / \mathrm{m}^{2}\right)$.

\section{Service utilization}

In Sri Lanka pre-pregnancy screening facilities are available free of charge at $\mathrm{MOH}$ level for women in reproductive age group. But most of them are underutilized. Among the 416 participants only 78 (18.8\%) had attended for pre-pregnancy screening, 312 (75\%) had not attended, 26 (6.3\%) didn't know there are such services.

Antenatal sessions are conducted at $\mathrm{MOH}$ level for the antenatal couples in order to educate them regarding pregnancy and postpartum period. Participation for these sessions were fairly high (64\%), only $1 \%$ didn't know there are such programs.

\section{Women's perception of their own weight}

Women's perception of their own weight is presented in Table 1 . The majority of underweight women (90\%), normal weight women $(73.5 \%)$ and obese women (67\%) identified themselves as such, however one forth $(23.8 \%)$ of normal weight women considered themselves as underweight. Fifty three percent (53\%) of overweight women identified themselves as such, but $45 \%$ of them considered themselves to be normal weight. Overweight women were the most likely to underestimate their own BMI category.

\section{Accuracy of estimation of recommended weight gain in pregnancy}

Most of the pregnant women in the study sample (59.6\%) were unable to estimate the recommended weight gain in pregnancy, whereas $17 \%$ were able to correctly estimate it.

Table 1. Accuracy of estimation of BMI by women in each category.

\begin{tabular}{|c|c|c|c|c|}
\hline \multirow{2}{*}{ Actual BMI category } & \multicolumn{4}{|c|}{ Perceived BMI category } \\
\hline & Under wt. (82) & Normal wt. (214) & Over wt. (84) & Obese (36) \\
\hline $\begin{array}{c}\text { Under wt } \\
\left(\mathrm{BMI}<18 \mathrm{~kg} / \mathrm{m}^{2}\right) \\
(40)\end{array}$ & $36(90 \%)$ & $4(10 \%)$ & 0 & 0 \\
\hline $\begin{array}{c}\text { Normal wt } \\
\left(\text { BMI } 18-24.9 \mathrm{~kg} / \mathrm{m}^{2}\right) \\
(193)\end{array}$ & $46(23.8 \%)$ & $142(73.5 \%)$ & $5(2.5 \%)$ & 0 \\
\hline $\begin{array}{c}\text { Over wt } \\
\left(\text { BMI } 25-29.9 \mathrm{~kg} / \mathrm{m}^{2}\right) \\
(134)\end{array}$ & 0 & $60(44.7 \%)$ & $71(53 \%)$ & $3(2 \%)$ \\
\hline $\begin{array}{c}\text { Obese } \\
\left(\mathrm{BMI}>30 \mathrm{~kg} / \mathrm{m}^{2}\right) \\
(49)\end{array}$ & 0 & $8(16 \%)$ & $8(16 \%)$ & $33(67 \%)$ \\
\hline
\end{tabular}




\section{Complications related to excessive gestational weight/obesity}

Seventy three percent $(73 \%, n=142)$ of women believed that excess gestational weight gain or obesity would be associated with increased pregnancy complications, however 17\% $(\mathrm{n}=9)$ doesn't know anything about it and 10\% $(\mathrm{n}=4)$ believed it would not lead to complications.

Although $73 \%$ gave positive responses, their knowledge on specific nature of these risks were poor; $51 \%$ of women identified problems related to pregnancy induced hypertension, 55.5\% identified gestational diabetes, 38\% identified the need for caesarian delivery and backache, $46 \%$ suggested persistent obesity after delivery. Less than $10 \%$ of pregnant women suggested the need for instrumental delivery, delay in wound healing, preterm birth and breast feeding problems as being related to excessive weight gain or obesity during pregnancy (Table 2).

Fifty eight percent (58\%) of women believed that there could be neonatal complications from excess gestational weight gain or obesity, however $27 \%$ doesn't know anything about it and $15 \%$ believed it would not lead to neonatal complications. Macrosomia and diabetes in later life were suggested by about $28 \%$ of the women (Table 3 ).

The Institute of Medicine (IOM) guidelines for weight gain in pregnancy formed the basis of "expert opinion" (Table 4).

Table 2. Pregnant women's knowledge on maternal complications related to excessive weight gain/obesity.

\begin{tabular}{cccc}
\hline Specific complication & Yes & No & Don't know \\
\hline Abortions & $76(18.3 \%)$ & $47(11.3 \%)$ & $293(70.4 \%)$ \\
Pregnancy Induced hypertension & $212(51 \%)$ & $54(13 \%)$ & $150(36.1 \%)$ \\
Gestational diabetes & $231(55.5 \%)$ & $52(12.5 \%)$ & $133(32 \%)$ \\
Need for caesarian delivery & $157(37.7 \%)$ & $37(8.9 \%)$ & $222(53.4 \%)$ \\
Need for instrumental delivery & $18(4.3 \%)$ & $54(13 \%)$ & $344(82.7 \%)$ \\
Delay in wound healing & $18(4.3 \%)$ & $56(13.5 \%)$ & $342(82.2 \%)$ \\
Preterm birth & $39(9.4 \%)$ & $54(13 \%)$ & $323(77.6 \%)$ \\
Breast feeding complications & $32(7.7 \%)$ & $36(8.7 \%)$ & $348(83.7 \%)$ \\
Backache & $153(36.8 \%)$ & $50(12 \%)$ & $213(51.2 \%)$ \\
Persistent obesity after delivery & $190(45.7 \%)$ & $24(5.8 \%)$ & $202(48.6 \%)$ \\
\hline
\end{tabular}

Table 3. Pregnant women's knowledge on neonatal complications related to excessive weight gain/obesity.

\begin{tabular}{cccc}
\hline Specific complication & Yes & No & Don't know \\
\hline Overweight babies (macrosomia) & $116(27.9 \%)$ & $70(16.8 \%)$ & $230(55.3 \%)$ \\
Birth trauma & $96(23.1 \%)$ & $43(10.3 \%)$ & $277(66.6 \%)$ \\
Congenital anomalies & $14(3.4 \%)$ & $49(11.8 \%)$ & $353(84.9 \%)$ \\
Neonatal hypoglycemia & $29(7 \%)$ & $45(10.8 \%)$ & $342(82.2 \%)$ \\
Perinatal mortality/still birth & $40(9.4 \%)$ & $46(11.3 \%)$ & $330(79.3 \%)$ \\
Childhood obesity & $64(15.4 \%)$ & $76(18.3 \%)$ & $276(66.3 \%)$ \\
Diabetes in later life & $122(29.3 \%)$ & $41(9.9 \%)$ & $253(60.8 \%)$ \\
\hline
\end{tabular}


Table 4. Women's beliefs about safe ways to manage weight gain in pregnancy.

\begin{tabular}{ccc}
\hline Ways to manage weight gain & Expert opinion & $\begin{array}{c}\text { No. (\%) of participants } \\
\text { answering correctly }\end{array}$ \\
\hline Have less soft drink & Yes & $290(69.7 \%)$ \\
Skip meals & No & $207(49.8 \%)$ \\
Choose low fat milk and dairy products & Yes & $239(57.5 \%)$ \\
Eat less cakes and chocolate & Yes & $258(62 \%)$ \\
Avoid exercises & No & $150(36 \%)$ \\
Drink more fruit juice & No & $55(13.2 \%)$ \\
Eat plenty of fruit and vegetables & Yes & $317(76.2 \%)$ \\
Exercise three or more times each week & Yes & $166(39.9 \%)$ \\
Eat for two & No & $132(31.7 \%)$ \\
Eat less take away foods/fast foods & Yes & $269(64.7 \%)$ \\
Eat less fried foods & Yes & $332(79.8 \%)$ \\
Eat low carbohydrate diet & No & $25(6 \%)$ \\
\hline
\end{tabular}

\section{Discussion}

In our present study maternal perception on obesity; its complications and gestational weight gain in pregnant mothers.

\section{Women's perception of their own weight}

Nearly $90 \%$ of the underweight women perceive them to be underweight; further $73 \%$ of the normal weight perceives them to be normal of normal weight. Majority of the patient who are overweight perceive as normal. $44 \%$ of the overweight women perceive them as normal.

$16 \%$ of the obese still felt them self as normal. Whereas $67 \%$ seems to have a accurate perception about their weight. Most of the pregnant women in the study sample (59.6\%) were unable to estimate the recommended weight gain in pregnancy, whereas $17 \%$ were able to correctly estimate it. Alexis Shub et al. in his recent study found that the majority (86.6\%) of normal weight women identified themselves as such, however nearly one in 10 considered they overweight. While around two-thirds of women accurately identified they were overweight, the remainder considered them to be normal weight. The majority of obese women considered themselves to be overweight and these women were the most likely to underestimate their own BMI category, with only $24 \%$ identifying themselves as very overweight. In our study nearly $60 \%$ of the obese perceive as normal need to be further evaluated.

Pregnant women's knowledge on maternal complications related to excessive weight gain/obesity

Seventy three percent (73\%) of women believed that excess gestational weight gain or obesity would be associated with increased pregnancy complications; however $17 \%$ doesn't know anything about it and $10 \%$ believed it would not lead to complications. Alexis Shub et al. found Ninety-four per cent of women be- 
lieved that excess GWG or obesity would be associated with increased pregnancy complications, but their knowledge of the specific nature of these risks was poor. It is apparent from our study $73 \%$ compare to $90 \%$ in western studies would be still favorable for a developing country.

Pregnant women's knowledge on neonatal complications related to excessive weight gain/obesity

Fifty eight percent (58\%) of women believed that there could be neonatal complications from excess gestational weight gain or obesity, however $27 \%$ doesn't know anything about it and $15 \%$ believed it would not lead to neonatal complications. Macrosomia and diabetes in later life were suggested by about $28 \%$ of the women and this percentage is totally unsatisfactory as it reflexes poor knowledge of pregnant women about neonatal complications.

Women's beliefs about safe ways to manage weight gain in pregnancy

Although the women are aware about traditional methods, they seem to be poorly knowledgeable about carbohydrate restriction as an effective method of weight loss. This effect possibly originates from lack of dietitian advice (medical nutrition therapy) in our clinics.

\section{Conclusion}

Most of our mothers still do not have correct perception about their weight especially among the overweight group. Significant proportion of mothers is aware about the maternal complications due to maternal obesity. There is poor awareness about neonatal complications and effective weight reducing strategies.

\section{Recommendations}

Since our conclusions are mostly related to overweight and obese women, the correct measurement of weight, referral to a dietician as well as seeking advice on losing weight are highly recommended.

Furthermore, the employment of medical officers specialized in food and nutrition on a full time basis will allow patients to receive proper nutritional advice (medical nutritional therapy) to overcome obesity and under nutrition.

Such services should also be modified to provide target information to further educate the patients about obesity, maternal, neonatal complications as well as provide logical and practical advice to lose weight with an effective follow-up.

\section{Acknowledgements}

Our sincere thanks and appreciation are extended to the following institutions and individuals for their assistance towards success of the research: medical officers, nurses and staff at medical clinic, University Obstetrics and Gynecology Unit, De Soyza Hospital for Women (DSHW), Colombo, Sri Lanka. We confirm the authenticity of this clinical research work and certify that these data have not been published elsewhere nor are currently under consideration for publication elsewhere. With the submission of this manuscript, we would like to undertake 
that all authors of this research paper have directly participated in the planning, execution or analysis of this study; all authors of this paper have read and approved the final version submitted.

\section{Conflicts of Interest}

The author(s) declared no potential conflicts of interest with respect to the research, authorship, and/or publication of this article.

\section{References}

[1] World Health Organization. (2013) Fact File: 10 Facts on Obesity. http://www.who.int/features/factfiles/obesity/en/

[2] Jayatissa, R., Hossain, S.M., Gunawardana, S., Ranbanda, J., Gunathilaka, M. and De Silva, P. (2012) Prevalence and Associations of Overweight among Adult Women in Sri Lanka: A National Survey. Sri Lanka Journal of Diabetes Endocrinology and Metabolism, 2, 61-68. https://doi.org/10.4038/sjdem.v2i2.4774

[3] Davis, S.E., Stack, J.J., Ellepola, H. and Haran, M. (2013) Obesity in Pregnancy-The Bigger Issues. Sri Lanka Journal of Obstetrics and Gynecology, 35, 29-33. https://doi.org/10.4038/sljog.v35i1.6002

[4] Fraser, A., Tilling, K., Macdonald-Wallis, C., Sattar, N., Brion, M.-J. and Benfield, L. (2010) Association of Maternal Weight Gain in Pregnancy with Offspring Obesity and Metabolic and Vascular Traits in Childhood. Circulation, 121, 2557-2564. https://doi.org/10.1161/CIRCULATIONAHA.109.906081

[5] Abeysena, C. and Jayawardana, P. (2010) Maternal and Social Determinants of Excessive Weight Gain during Pregnancy: A Cohort Study. International Journal of Collaborative Research on Internal Medicine and Public Health, 2, 348-359.

[6] Callaway, L.K., O'Callaghan, M.J. and McIntyre, H.D. (2009) Barriers to Addressing Overweight and Obesity before Conception. The Medical Journal of Australia, 191, 425-428.

[7] Shub, A., Huning, E.Y., Campbell, K.J. and McCarthy, E.A. (2013) Pregnant Women's Knowledge of Weight, Weight Gain, Complications of Obesity and Weight Management Strategies in Pregnancy. BMC Research Notes, 6, 278. https://doi.org/10.1186/1756-0500-6-278

[8] Department of Census and Statistics. (2007) Sri Lanka Demographic and Health Survey 2006/7, Sri Lanka.

[9] Family Health Bureau. (2011) Maternal Care Package-A Guide to Field Healthcare Workers.

[10] Abeysena, C. and Jayawardana, P. (2011) Sleep Deprivation, Physical Activity and Low Income Are Risk Factors for Inadequate Weight Gain during Pregnancy: A Cohort Study. Journal of Obstetrics and Gynaecology Research, 37, 734-740. https://doi.org/10.1111/j.1447-0756.2010.01421.x

[11] Lwanga, S.K., Lemeshow, S. and World Health Organization. (1991) Sample Size Determination in Health Studies: A Practical Manual.

[12] Shub, A. and Huning, E.Y.-S. (2013) Pregnant Women's Knowledge of Weight, Weight Gain, Complications of Obesity and Weight Management Strategies in Pregnancy. BMC Research Notes, 6, 278. 